\title{
DESAIN KEMASAN ANEKA DODOL BERBASIS BAHAN BAKU LOKAL SEBAGAI OLEH-OLEH KHAS LIWA LAMPUNG BARAT
}

\section{DESIGN OF VARIOUS DODOL PACKAGING BASED ON LOCAL RAW MATERIALS AS A TYPICAL SOUVENIRS OF WEST LAMPUNG LIWA}

\author{
${\text { Analianasari1a }{ }^{1} \text { D Berliana }}^{1}$, T S Jaya ${ }^{1}$ \\ 'Program Studi Agribisnis, Jurusan Ekonomi dan Bisnis, \\ Politeknik Negri Lampung, Jl. Soekarno Hatta No 10 Rajabasa Lampung \\ aKorespondensi: Analianasari; E-mail: analianasari@polinela.ac.id \\ (Diterima: 23-08-2019; Ditelaah: 24-08-2019; Disetujui: 31-03-2020)
}

\begin{abstract}
KWT Sekar Wangi is one of the women farmer mobilization groups to empower women to make dodol based on local raw materials as souvenirs from Liwa Lampung Barat. Dodol produced from the raw material of tomatoes, squash, Dutch eggplant and coffee. Dodol is a souvenir product typical of Liwa Lampung Barat must have specificities such as raw materials and product packaging. The purpose of this activity is to design packaging that characterizes the distinctiveness of the West Lampung Regency by using ceulugham batik patterns. Ceulugham batik on dodol product packaging is expected to highlight the identity of Sekar Wangi KWT products as souvenirs from Liwa West Lampung. This activity is to support the diversification of processing based on local raw materials as a distinctive product for West Lampung as a tourist destination in Lampung Province.
\end{abstract}

Keywords: Dodol, souvenirs of west lampung, packaging design, packaging.

\begin{abstract}
ABSTRAK
KWT Sekar Wangi adalah salah satu kelompok penggerak wanita tani untuk memberdayakan wanita membuat olahan dodol berbasis bahan baku lokal sebagai oleh-oleh khas Liwa Lampung Barat. Dodol yang diproduksi beraasal dari bahan baku tomat, labu siam, terong belanda dan kopi. Dodol sebagai produk oleh-oleh khas Liwa Lampung Barat harus memiliki kekhasan seperti bahan baku dan kemasan produk. Tujuan kegiatan ini adalah mendesain kemasan yang mencirikan kekhasan Kabupaten Lampung Barat dengan menggunakan corak batik ceulugham. Batik Ceulugham pada kemasan produk dodol diharapkan dapat menonjolkan identitas produk KWT Sekar Wangi sebagai oleh-oleh khas Liwa Lampung Barat. Kegiatan ini untuk mendukung diversifikasi olahan berbasis bahan baku lokal sebagai produk khas oleh-oleh Lampung Barat sebagai kabupaten destinasi wisata di Provinsi Lampung.
\end{abstract}

Kata kunci : Desain kemasan, dodol, oleh-oleh Lampung Barat, Kemasan produk.

Analianasari., Berliana, D., Jaya, T. S. (2019).Desain Kemasan Aneka Dodol Berbasis Bahan Baku Lokal Sebagai Oleh- Oleh Khas Liwa Lampung Barat. Jurnal Qardhul Hasan : Media Pengabdian kepada Masyarakat, 6(1) 1-7.

\section{PENDAHULUAN}

KWT Sekar Wangi adalah Kelompok Wanita Tani yang sudah dibentuak sejak tahun 2008 oleh Sri Yuni dan saat ini sudah beranggotakan 40 orang. Awal terbentuknya KWT ini adalah dilihat kondisi komoditas pertanian pada saat panen mengalami lonjakan harga yang rendah sehingga tercetus ide untuk mengolah komoditas pertanian menjadi produk olahan makanan. Produk olahan makanan yang dihasikan adalah dodol tomat, dan dodol labu siam. 
Aneka variasi dodol yang diproduksi KWT Sekar Wangi menjadikan dodol sebagai makanan khas oleh-oleh Liwa Kabupaten Lampung Barat. Susilawaty, (2016) menyatakan bahwa banyaknya masyarakat sekitar 98 persen yang berkunjung ke destinasi wisata akan membeli oleh-oleh khas suatu daerah. Konsumen dalam membeli produk biasanya memperhatikan kemasan sebelum memutuskan pembelian produk (Darmawan, 2017). Pengemasan bertujuan untuk melindungi produk dan memberikan tampilan yang menarik. Kemasan produk yang baik memuat informasi tentang identitas produk termasuk berat, tanggal kemasan, tanggal kadaluarsa, jenis produk, dan komposisi. Desain kemasan yang menarik untuk mendapatkan nilai tambah sehingga memberikan emotional benefit pada konsumen (Cenadi, 2000).

Kemasan aneka dodol KWT Sekar Wangi pada awalnya berupa kemasan plastik biasa dan pemasaran hanya terbatas pada daerah sekitar Kabupaten Lampung Barat. Namun, pemerintah daerah selalu mengajak KWT Sekar Wangi untung berpartisipasi dalam setiap kegiatan acara seperti Gebyar Lumbok Seminung (29 April 2018), Festival Begual Jejama (12-14 April 2018), Festival Sekala Bekhak (10-12 Juli 2018), Festival Kopi Lampung Barat (21-23 Juli 2018), dan kegiatan yang sudah dijadwalkan adalah Festival Santri (11 September 2018), Liwa Fair (15-21 September 2018), Souh Trail Adventure (30 September 2018), dan Festival Kebangsaan (9- 14 November 2018). Kegiatan yang rutin dilaksanakan oleh Pemda Lampung Barat bertujuan untuk menarik wisatawan domestik dan mancanegara untuk datang menikmati keindahan daerah Lampung Barat dan tentu saja meningkatkan pendapatan daerah. Kegiatan pemerintah daerah yang selalu melibatkan KWT Sekar Wangi untuk menyediakan unggulan produk oleh-oleh Lampung Barat selain kopi bubuk tentu saja menjadi peluang pemasaran produk dodol yang sangat baik. Permasalahan kemasan produk aneka dodol yang belum menonjolkan keunggulan produk sebagai produk sehat bebas pengawet, mengandung antioksidan dan serat pangat karena menggunakan bahan baku alami (tomat, labu siam). Selain itu, ciri khas daerah sangat penting untuk ditampilkan dalam desain kemasan untuk memperkenalkan daerah ke konsumen. Oleh sebab itu, tujuan kegiatan ini adalah penggunaan batik khas Lampung Barat "Celugam" untuk memperkaya desain kemasan pada produk aneka dodol Kwt Sekar Wangi.

\section{MATERI DAN METODE}

\section{Tempat dan Waktu Pelaksanaan}

Kegiatan Pengabdian Kepada Masyarakat dilaksanakan di KWT Sekar Wangi Desa Sekincau Kecamatan Sekincau Kabupaten Lampung Barat pada tanggal 13 Juli 2019.

\section{Partisipasi Kegiatan}

Kegiatan pengabdian ini dihadiri oleh target sasaran yaitu KWT Sekar Wangi, Kepala Desa, Petugas Penyuluh Lapangan (PPL) dan masyarakat sekitar Desa Sekincau.

\section{Metode Penyelesaian Masalah}

Kegiatan pengabdian ini bertujuan untuk meningkatkan keterampilan dan pengetahuan anggota KWT melalui diskusi dan demontrasi dalam pengemasan produk.

Metode diskusi dan penyuluhan adalah dengan memaparkan materi pentingnya kemasan, dan faktor-faktor yang dapat mempengaruhi keputusan konsumen dalam memutuskan pembelian produk. Metode demontrasi adalah melaksanakan pembuatan macam-macam bentuk kemasan dari bahan plastic $0,8 \mathrm{~mm}$ dan paper bag dengan kertas Samson.

Tahapan pelaksanaan kegiatan ada 3 tahap yaitu tahap sosialisasi, pelatihan pengemasan, dan Evaluasi. Tahap sosialiasi merupakan tahap mensosialisasikan kegiatan pada anggota KWT dan pamong desa untuk memberikan pelatihan pengemasan produk aneka dodol. Tahap 
selanjutnya adalah melaksanakan kegiatan pelatihan pembuatan macam-macam kemasan pada anggota kelompok KWT Sekar Wangi. Selain pelatihan pembuatan kemasan, tim memberikan materi penghitungan harga jual produk dengan memasukkan kemasan yang baru sebagai penghitungan biaya variabel. Tahap selanjutnya adalah evaluasi melalui diskusi dengan proses pendekatan.

\section{HASIL DAN PEMBAHASAN}

\section{Metode Pelaksanaan}

Kegiatan Pengabdian bertujuan untuk mengatasi permasalahan KWT Sekar Wangi untuk meningkatkan penjualan produk aneka dodol berbasis bahan baku local sebagai produk unggulan daerah yang memiiki kekhasan buah tangan (oleh-oleh) dari Liwa Lampung Barat sehingga dilakukan metode pemecahan masalah sebagai berikut:

\section{Metode Desain Kemasan}

Kemasan merupak kunci utama dalam pemasaran produk, namun kemasan yang menarik harus memiliki kriteria simple (sederhana), fungsional dan menciptakan respon emosional positip. Desain kemasan yang menarik memberikan sebuah nilai tambah produk yang dikemasnya (Cenadi, 2000). Nurviana et al., (2012) telah mewawancarai pengrajin dodol garut yang mendesain kemasannya dengan mencirikan budaya pada kemasannya. Pada tahun 2009 muncul kreasi baru, dodol yang dibalut dengan cokelat yang bersifat padat. Produsen juga berkreasi dengan kemasan luarnya, yaitu dengan mengambil gagasan dari besek. Ukuran besek diperkecil, diberi warna dan diberi label yang warnanya serasi dengan kemasan. Selain itu, tempat penjualan pun ditata modern. Upaya ini mendapat respon yang baik dari wisatawan. Produsen mengantisipasi dengan memperbanyak ragam rasa dan produk, diikuti dengan pengembangan kemasan yang dilakukan dengan bekerja sama dengan pengrajin setempat.

Desain kemasan aneka dodol Sekar Wangi memiliki beberapa fungsi, yaitu:

\section{Fungsi Informasi}

Fungsi informasi pada kemasan aneka dodol Sekar Wangi memuat pesan yang berisikan identitas dan informasi konten produk. Konten produk memuat komposisi, keterangan kadaluarsa, cara menyimpan, dan berat isi (Gambar 1). Hal ini sesuai dengan aturan ketentuan Undang-undang Label dan Pangan Tahun 1999 sehingga desain yang beredar di masyarakat memenuhi aspek hukum yang memuat informasii konten produk yang dikemas. Gambar 1. Produk dodol.

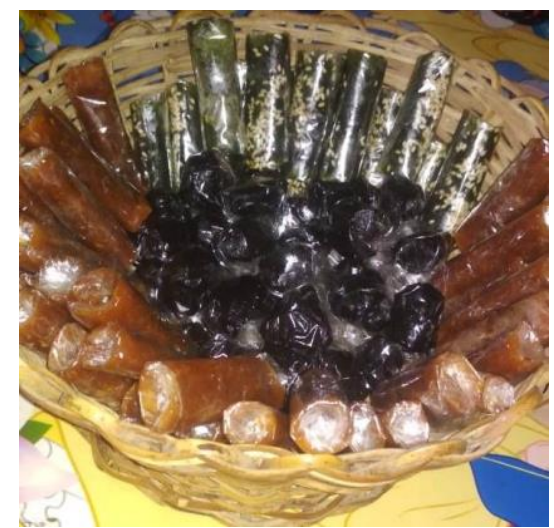

Gambar 2. Konten Produk Dodol SW pada Kemasan.

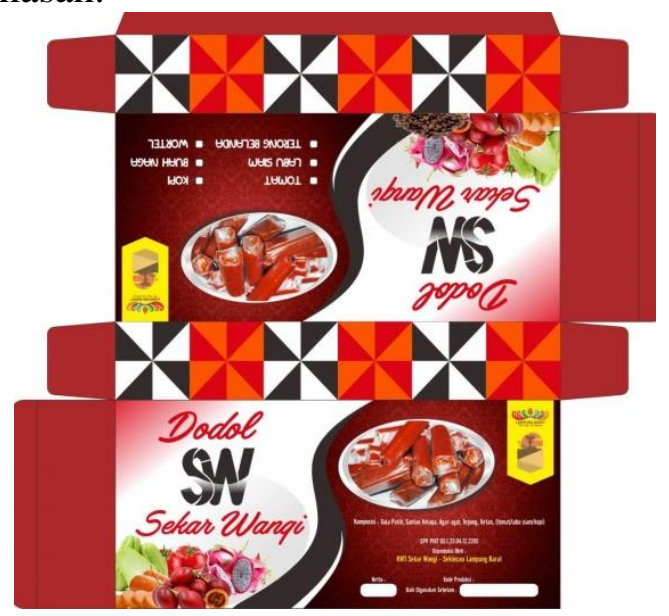

\section{Fungsi Tampilan}

Fisik kemasan bentuk luar kemasan mengambil gagasan dari kertas karton dengan mencirikan batik ceulugham khas Liwa Lampung Barat (Gambar 2a), begitu juga untuk label pada plastik kemasan. 
Gambar 3. Batik Celugam Lampung Barat.

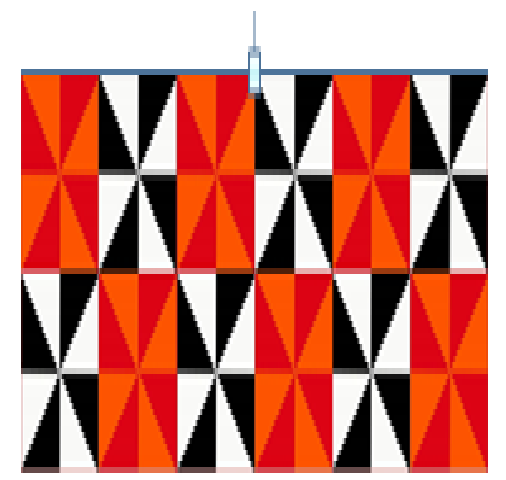

Gambar 4. Label produk untuk kemasan plastik.

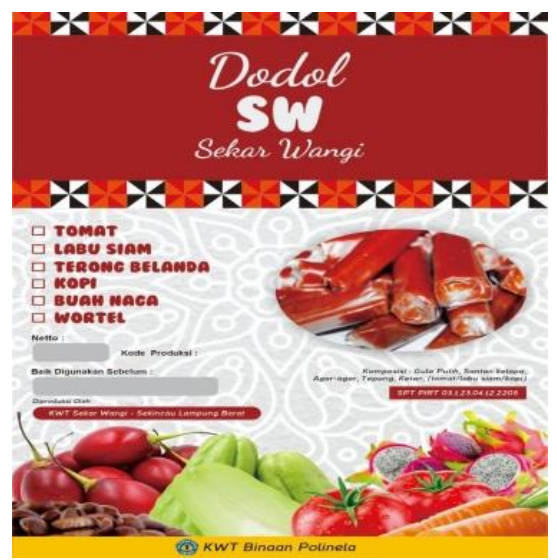

Gambar 5. Produk aneka dodol dalam kemasan plastik.

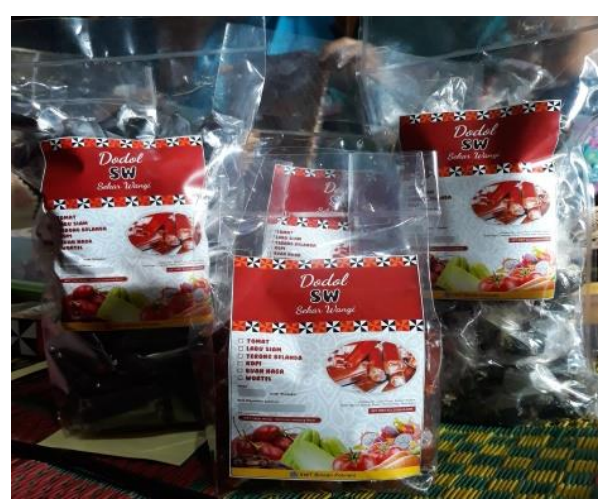

Kemasan sekunder berbahan kertas concord Gambar 1, kemasan primer berbahan plastik Gambar 1. Cara pengemasan pada dodol SW adalah produk dikemas yang sudah dilapisi dengan plastik selanjutnya dimasukkan kedalam kotak atau kemasan plastik Gambar 5. Kontekstualitas budaya pada kemasan Oleh-ole, kontekstualitas Budaya pada Kemasan Oleholeh Tampilan kemasan mengambil gagasan dari batik khas liwa Lampung Barat yaitu batik Celugham Gambar 2 bertujuan untuk memperkenalkan batik liwa melalui kemasan produk oleh-oleh.Identitas pada Kemasan Oleh-oleh identitas kemasan pada produk dodol SW dapat dipahami oleh konsumen melalui gambar yang sudah terdapat pada kemasan. Identitas jenis dodol sudah disiapkan pada kemasan maupun label berupa kotak kecil yang dapat di contreng oleh KWT Sekar Wangi berdasarkan bahan baku yang dioalah (Gambar 1, dan 2).

Pengamasan produk dodol SW yang telah memiliki identitas tentang produk dan ciri khas suatu daerah menjadikan dodol ini lebih unggul dari pesaingnya karena produk pesaing masih menggunakan plastic ataupun plastik mika. Davita et al., (1989) melaporkan bahwa kemasan dapat menampilkan identitas yang jelas sebagai oleh-oleh khas Pulau Lombok, dengan memenuhi kriteria dan karakteristik dari produk, baik dari segi inovasi dan estetika dengan menampilkan beberapa elemen desain khas Lombok yang membuat kemasan lebih menarik dan dapat bersaing dengan kompetitor lainnya. Produk dodol khas liwa Lampung Barat.

\section{Pelatihan Pengemasan Aneka Dodol}

Kemasan yang menarik dan unik cenderung memberikan kesan positif terhadap penjualan dan daya saing produk. Saat ini konsumen cukup cerdas untuk menilai suatu produk melalui

Kemasannya Dahlia et al., (2019) menyatakan bahwa kemasan dapat meningkatkan penjualan produk dan membangun ekuitas merek.

Kemasan yang digunakan dalam produk aneka dodol SW sebelumnya belum menciirikan kekhasan suatu daerah, sederhana, menggunakan plastik biasa, dan kemasan mica Gambar 6.

Gambar 6.Kemasan Produk Dodol SW sebelum mendapatkan Program Pengabdian Kepada Masyarakat. 


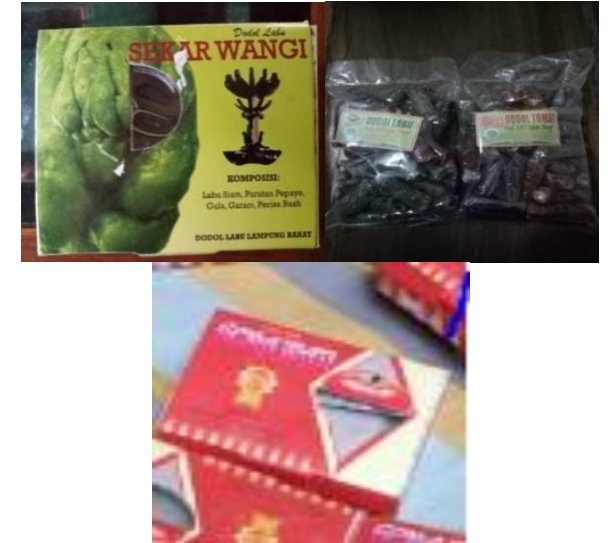

Berdasarkan permasalahan

masih sederhana jenis kemasan pada produk dodol aneka rasa sehingga tim PKM dari Politeknik Negeri Lampung memberikan pelatihan pengemasan jenis-jenis kemasan untuk olahan pangan. Jenis kemasan yang digunakan ada 3 (tiga) jenis bahan, yaitu :

\section{Plastik Poly Propylene (pp)}

Plastik pp merupakan plastik yang memiliki bahan yang ringan, fleksibel (mudah dibentuk) transparan, dan jernih, serta kekuatan tarik yang lebih besar dibandingkan Poly Ethylene (PE) sehingga tidak mudah sobek Gambar 7.

Gambar 7. Plastik Poly Proplene (pp) cap Bawang.

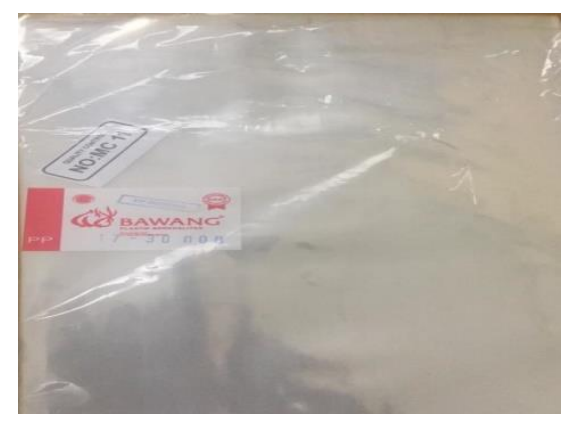

\section{Kertas Samson}

Kertas samson umumnya berwarna coklat muda dan permukaannya kasar, kertas ini merupakan hasil daur ulang. Kertas Samson digunakan untuk membungkus produk karena memiliki kesan klasik, biasa dibuat untuk paperbag. Kertas ini dicetak 1-2 warna yaitu coklat dan hitam dengan berat 150 gr dan 220 gr (karton) Gambar 8.

\section{Gambar 8. Kertas Samson (Samson Kraft)}

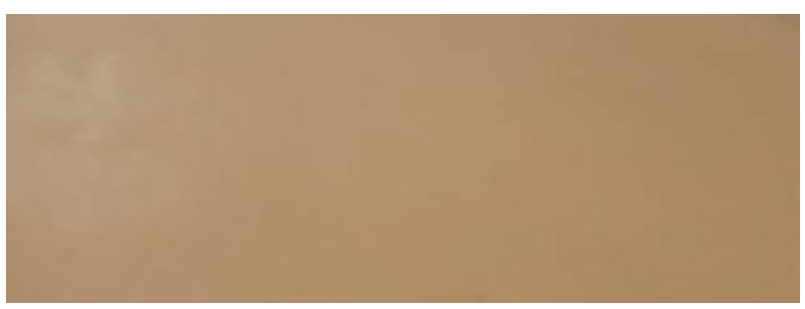

\section{Kertas Ivory}

Bahan kertas ivory hampir sama dengan art karton, kedua sisinya putih, tetapi tidak Seputih art karton yang membedakan art karton sisinya licin, sementara ivory hanya salah satunya yang licin. Berat kertas ivory yang digunakan adalah 210 gr Gambar 9. Gambar 9. (a) Kertas Ivory bagian dalam; (b) Kertas Ivory bagian luar

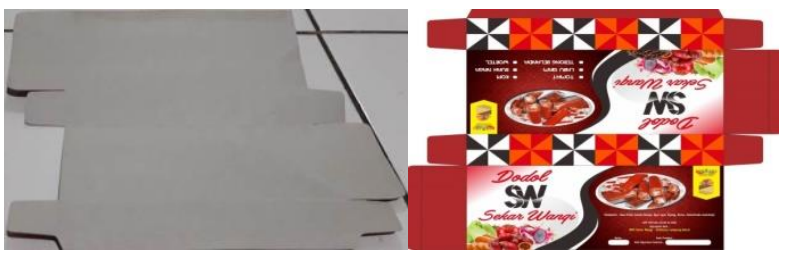

(a)

(b)

Pelatihan kemasan yang dilaksanakan pada kegiatan ini dilakukan pada anggota KWT Sekar wangi sekitar 20 orang dengan membuat 3 jenis bentuk kemasan dari pastik dan 1 jenis dari kertas yaitu membuat paper bag Gambar 10.

Gambar 10. Bentuk Standing pouch (a), Gusset (b), Simple Standing Pouch (c) dan Paper bag (d).

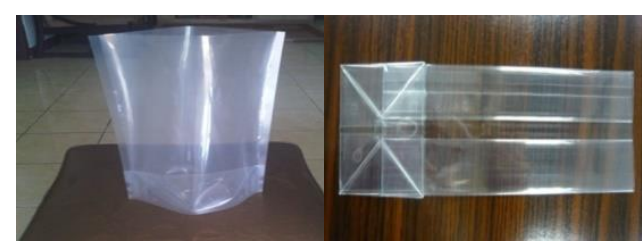

(a)

(b)

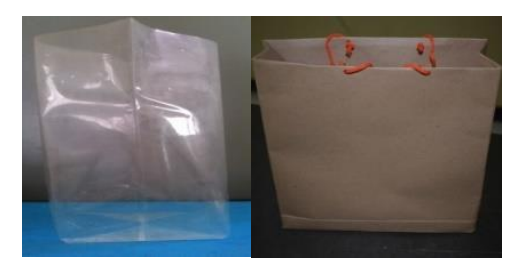

(c)

(d) 
Gambar 8. Kegiatan Pelatihan Kemasan produk aneka dodol Sekar Wangi.

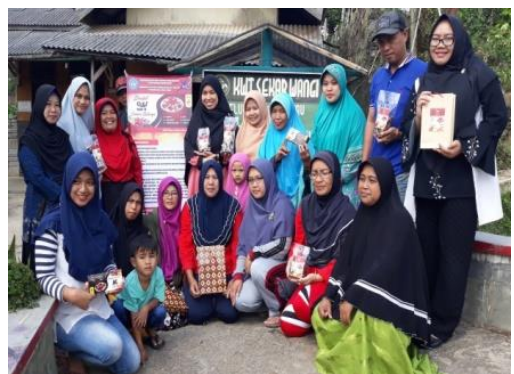

Pengemasan yang digunakan sebagai pelindung produk aneka dodol sebagai barang dagangan (niaga). Kemasan yang dibuat anggota ada beberapa yang rapi dan dapat diandalkan sebagai pembuat kemasan di KWT Sekar Wangi. Ketekunan dan ketelitian dalam membuat kemasan pada masing-masing anggota KWT, membuat semangat baru untuk mengembangkan pemasaran lebih luas.

Kemasan paper bag merupakan kemasan yang menjadi favorit anggota KWT karena dapat dijadikan kemasan pendukung sebagai wadah oleh-oleh aneka dodol Sekar Wangi. Kemasan ini berbentuk persegi panjang dengan ukuran 19,5 cm x 10,8 cm x $27,7 \mathrm{~cm}$.

\section{KESIMPULAN}

Desain kemasan oleh-oleh aneka dodol sekar wangi sudah menunjukkan ciri khas suatu daerah dengan batik ceulugham sehingga menjadi sarana media komunikasi sekaligus promosi Liwa sebagai daerah destinasi wisata. Ciri Khas batik ceulugham pada kemasan merupakan identitas yang jelas sebagai oleh-oleh Khas Liwa Lampung Barat yang membuat kemasan lebih menarik dan dapat bersaing dengan kompetitor lainnya. Desain kemasan produk dodol Sekar Wangi dapat memperluas pemasaran sehingga meningkatkan produksi dodol Sekar wangi. Peningkatan produksi tersebut dapat meningkatkan pendapatan keluarga sekaligus perekonomian pedesaan.

\section{SARAN}

Dibutuhkan penyegaran secara berkala dan pemantauan dari pihak perguruan tinggi agar hasil sertifikasi PIRT yang telah diperoleh mampu berjalan secara konsisten.

\section{UCAPAN TERIMAKASIH}

Penulis mengucapkan banyak terima kasih kepada dengan pendanaan Direktorat Riset dan Pengabdian Masyarakat Direktorat Jenderal Penguatan Riset dan Pengembangan Kementerian Riset, Teknologi, dan Pendidikan Tinggi Sesuai dengan Kontrak Penelitian Nomor:023/SP2H/PPM/DRPM/2019.

\section{DAFTAR PUSTAKA}

Cenadi, C.S. 2000. Peranan Desain Kemasan Dalam Dunia Pemasaran. Nirmana, 2(2): 92-103. Tersedia di http://puslit2.petra.ac.id/ejournal/ind ex.php/dkv/article/view/16056.

Dahlia, D., Nuraeni, N. \& Hadijah, H. 2019. Pemberdayaan Masyarakat Nelayan Mealui Pengolahan Ikan untuk Mendukung Program MP3 Pemerintah Kabupaten Majene. Jurnal Dedikasi Masyarakat, 2(2): 52-58.

Darmawan, D. 2017. Pengaruh Kemasan dan Harga Terhadap Keputusan Pembelian Produk Sayuran Hidroponik. Agrimas, 1(April): 1-10.

Davita, V., Yuwono, E.C. \& Soewito, B.M. 1989. Perancangan Desain Kemasan Dodol Produk. 1-10. Tersedia di publication.petra.ac.id/index.php/dkv /article/download/7293/6610.

Nurviana, N., Sunarto, P. \& Syarief, A. 2012. Identitas dan Karakter Budaya Lokal Pada Kemasan Makanan Oleh-Oleh. Wimba, Jurnal Komunikasi Visual dan Multimedia, 4(2): 1-16.

Susilawaty, D. 2016. Kontribusi Oleh-Oleh dalam Dunia Pariwisata. Koran Republika, (September): 2016.

Yusuf, M., Usdyana, N.F., Negeri, P., Pandang, U., Pertanian, P. \& Pangkep, N. 2018. 
Pemberdayaan kelompok wanita tani melalui diversifikasi pangan di kecamatan buntu batu kabupaten enrekang. 1(2): 98-108. 